\title{
Friedreich Ataxia: Clinical Feature and Electrophysiological Symptoms
}

Friedreich ataxia is inherited as an autosomal recessive disorder involving the spinocerebellar tracts, dorsal columns in the spinal cord, the pyramidal tracts, and the cerebellum and medulla. The majority of patients bear a recessive GAA triplet-repeat expansion on intron 1 of both alleles while a minority carry an expansion on allele and a point mutation or deletion on the other ${ }^{[1,2]}$ The disease-causing genotype leads to decreased production of frataxin. Mutations cause oxidative injury associated with excessive iron deposits in mitochondria; frataxin deficiency leads to mitochondrial iron accumulation, deficient production of adenosine triphosphate, and a potential rise in free radical generation. ${ }^{[1,2]}$ These events lead to onset of a variety of symptoms, such as gait disturbance, loss of sensation, areflexia, and dyscoordination, beginning usually between ages 5 and 15 years although later onset is not uncommon. ${ }^{[3]}$

Approximately two-thirds of individuals with Friedreich ataxia have cardiomyopathy and up to $30 \%$ have diabetes mellitus. ${ }^{[4]}$ The loss of frataxin function in mitochondria accounts for these pathogenic processes in Friedreich ataxia. Mitochondria are essential for the sensing of nutrients by the $\beta$ cell and for the generation of signals that trigger and amplify insulin secretion, known as stimulus-secretion coupling. Moreover, in the intrinsic pathway of apoptosis, pro-apoptotic signals converge on mitochondria, resulting in mitochondrial Bax translocation, membrane permeabilization, cytochrome $\mathrm{c}$ release and caspase cleavage. ${ }^{[5]}$

The ataxia is slowly progressive and involves the lower extremities to a greater degree than the upper extremities.
In general, results of electrophysiologic studies including visual, auditory brainstem, and somatosensory-evoked potentials are often abnormal. ${ }^{[6]}$

In the article "Diabetes Mellitus as the Presenting Feature of Friedreich Ataxia,"[7] the authors report a case of an 8-year girl who initially presented with diabetic ketoacidosis and was treated as case of insulin dependent diabetes mellitus. Furthermore, they report an axonal type of generalized sensory neuropathy and lower MCV in tibial nerve. The authors assumed the diagnosis of Friedreich ataxia for the patient. However, neuroimaging and FXN gene analysis were not conducted. The co-morbidity of diabetes mellitus and peripheral neuropathy can also result from mitochondrial disorders, and could represent a complication of hereditary motor and sensory neuropathy ${ }^{[8]}$ in a diabetic patient by chance. In addition, atypical Friedreich ataxia due to compound heterozygosity for FXN GAA expansion and a point mutation may present a greater diagnostic dilemma.

Masayoshi Oguri

Department of Pathobiological Science and Technology, Faculty of Medicine, Tottori University, Yonago, Japan

Address for correspondence: Dr. Masayoshi Oguri, Department of Pathobiological Science and Technology, Faculty of Medicine, Tottori University, Nishi-cho 86, Yonago, Japan. E-mail: o-masayoshi@med.tottori-u.ac.jp

\section{REFERENCES}

1. Deutsch EC, Santani AB, Perlman SL, Farmer JM, Stolle CA, Marusich MF, et al. A rapid, noninvasive immunoassay for 
frataxin: Utility in assessment of Friedreich ataxia. Mol Genet Metab 2010;101:238-45.

2. Pandolfo M. Friedreich ataxia: The clinical picture. J Neurol 2009;256 Suppl 1:3-8.

3. Isaacs CJ, Brigatti KW, Kucheruk O, Ratcliffe S, Sciascia T, McCormack SE, et al. Effects of genetic severity on glucose homeostasis in Friedreich ataxia. Muscle Nerve 2016;54:887-94.

4. Bidichandani SI, Delatycki MB. Friedreich ataxia. In: Pagon RA, Adam MP, Ardinger HH, Wallace SE, Amemiya A, Bean LJ, et al., editors. GeneReviews ${ }^{\circledR}$. Seattle, WA: University of Washington, Seattle; 1993-2017; 1998. Available from: https:// www.ncbi.nlm.nih.gov/books/NBK1281/. [Last updated on 2017 Jun 01].

5. Cnop M, Mulder H, Igoillo-Esteve M. Diabetes in Friedreich ataxia. J Neurochem 2013;126 Suppl 1:94-102.

6. Robert MK, Richard EB, Hal BJ, Bonita MD, editors. Nelson Textbook of Pediatrics. USA: Saunders Elsevier; 2007.

7. Garg M, Kulkarni SD, Shah KN, Hegde AU. Diabetes mellitus as the presenting feature of Friedreich's ataxia. J Neurosci Rural Pract 2017;8 Suppl S1:117-9.
8. Delatycki MB, Corben LA. Clinical features of Friedreich ataxia. J Child Neurol 2012;27:1133-7.

This is an open access article distributed under the terms of the Creative Commons Attribution-NonCommercial-ShareAlike 3.0 License, which allows others to remix, tweak, and build upon the work non-commercially, as long as the author is credited and the new creations are licensed under the identical terms.

\begin{tabular}{|l|l|}
\hline \multicolumn{2}{|c|}{ Access this article online } \\
\hline Quick Response Code: & Website: \\
\hline
\end{tabular}

How to cite this article: Oguri M. Friedreich Ataxia: Clinical feature and electrophysiological symptoms. J Neurosci Rural Pract 2017;8:691-2.

(c) 2017 Journal of Neurosciences in Rural Practice | Published by Wolters Kluwer - Medknow 